\title{
Retraction Note to: Balancing hyperbole and impact in research communications related to lead-free piezoelectric materials
}

\author{
Andrew J. Bell ${ }^{1, \star}$ and Dragan Damjanovic ${ }^{2}$ \\ ${ }^{1}$ School of Chemical and Process Engineering, University of Leeds, Leeds, UK \\ ${ }^{2}$ Group for Ferroelectrics and Functional Oxides, Ecole Polytechnique Fédérale de Lausanne, Lausanne, Switzerland
}

Published online:

24 March 2020

(C) Springer Science+Business

Media, LLC, part of Springer

Nature 2020

Retraction Note to:

J Mater Sci (2019) 54:11759-11762.

https://doi.org/10.1007/s10853-019-03733-z

The authors have retracted this article [1] due to a breach in confidentiality. The confidential information has been redacted to protect the privacy of those involved. The authors have been invited to re-submit a modified version of their manuscript for publication.
All authors agree with this retraction.

[1] Bell, A.J., Damjanovic, D. Balancing hyperbole and impact in research communications related to lead-free piezoelectric materials. J Mater Sci 54, 11759-11762 (2019). https://doi.org/10.1007/s10853019-03733-z.

Publisher's Note Springer Nature remains neutral with regard to jurisdictional claims in published maps and institutional affiliations.

The original article can be found online at https://doi.org/10.1007/s10853-019-03733-z.

Address correspondence to E-mail: A.J.Bell@leeds.ac.uk 